demand for their resources is greater than ever. There is a role for areas that are strictly off-limits, but most reefs should be, and with the right approach could be, managed by the people who depend on them.

This point is made strongly for the marine environment in general throughout the Atlas, but the section on 'The challenge of conservation' is so general and theoretical that it gives little impression of what is happening on the ground, despite the many innovative, interesting and potentially successful approaches to management being used. The IUCN's Marine programme is barely mentioned, despite its involvement in successful projects, such as Oman's coastal zone management plan. Descriptions of case studies would have been useful, such as marine parks that are working, efforts at community management of marine resources, and how and why international and regional treaties are so important for the marine environment. It is hoped that the important topics and problems raised in both these books will stimulate the appearance of other publications showing possible solutions.

Sue Wells.

\section{Mammals of the Neotropics, The Southern Cone, Volume 2 Chile, Argentina, Uruguay, Paraguay, by Kent H. Redford and John F. Eisenberg (The University of Chicago Press, 1992, ISBN 0226706826,430 pp., SB $€ 31.50, \$ 39.50$ )}

This is the second volume of a planned three-volume work, which will be the first complete account of the mammals of South America. The first volume dealt with Panama, Colombia, Venezuela, Guyana, Surinam and French Guiana. This volume covers the 360 mammal species of Chile, Argentina, Uruguay and Paraguay. The area is physically diverse, dominated by the Andes Mountains but also including areas of desert, steppe, dry forest and temperate rain forest. The book has chapters for each mammalian order, each starting with a diagnosis and comments on reproduction, information on distribution and a discussion of history and classification. The chapter is then subdivided into sections for families, genera and species. For each subdivision there is a diagnosis or description, information on distribution, life history and ecology and, for species, a table of measurements and a distribution map. Chapters also include detailed reference lists. The book finishes with chapters on mammalian community ecology and the effects of man. The result is an excellent and very comprehensive account. It will be of value to a wide range of people, from taxonomists to lay readers. It is well illustrated with useful skull drawings, and black-and-white and colour plates depicting a selection of mammal species. The only disappointment is that there are not more of these excellent plates. This book is a must for anyone with an interest in South America and it is very keenly priced. I await with great interest the publication of the third volume in the series, which will cover the mammals of central South America but, apparently, this work is still in its early stages.

Simon Mickleburgh.

\section{Fishes of the Great Basin: A}

Natural History, by William F. Sigler and John $W$. Sigler (University of Nevada Press, Reno, 1992, ISBN 0874171164 , 448 pp., HB £30)

This volume is one of a series covering various aspects of the natural history of the Great Basin in Utah, Wyoming, Idaho, Nevada, California and Oregon in the United States. The book begins with chapters on the Great Basin drainage area, a history of fishing in the area, the Endangered Species Act and desert fishes, the evolution and classification of fishes and fish biology and ecology. There follows a key to the native and introduced fishes of the area. The main part of the book is a detailed account of over 90 species that occur in the Basin. For each species there is an account of its economic importance, its range, a physical description, and information on size, longevity, food, feeding patterns, breeding habits, limiting factors and habitat. A final section on the preservation of the species relates mainly to the importance to the fishing industry. Rather confusingly there follows an annotated checklist containing more information for species already described in the main species section. The book finishes with appendices on the established fishes of the Great Basin and a list of fishes mentioned in the text that do not appear in the first appendix or the annotated checklist. A small number of species are illustrated with colour plates.

Overall, the book is confusingly laid out with information on species appearing in a number of places. Information on the conservation of endangered species is very limited. In the preface the authors stress that the amount of information presented for each species is directly proportional to its economic and ecological importance. Little-known highly endangered and localized species may thus receive scant attention. The book is heavily slanted towards the fishing 